\title{
PENERAPAN PERILAKU JUJUR MELALUI PEMBELAJARAN PENDIDIKAN KEWARGANEGARAAN DI SEKOLAH DASAR
}

\author{
Awalia Marwah Suhandi $^{1}$, Dinie Anggraeni Dewi², Yayang Furi Furnamasari ${ }^{3}$ \\ ${ }^{1,2,3}$ Program Studi Pendidikan Guru Sekolah Dasar, Universitas Pendidikan Indonesia, \\ Kampus Daerah Cibiru \\ 1Email: awaliamarwah@upi.edu
}

\begin{abstract}
ABSTRAK
Perilaku jujur merupakan kunci untuk pendidikan yang lebih baik. Dalam hal ini pendidikan seakan tutup telinga menanggapi berbagai permasalahan terkait permasalahan jujur tersebut. Untuk itu diperlukan sebuah solusi untuk meminimalisirnya. Solusi yang strategis untuk mengatasi permasalahan tersebut adalah dengan dilakukakkannya pembelajaran pendidikan kewarganegaraan di sekolah dasar. Tujuan dilakukannya penelitian ini adalah untuk menerapkan perilaku hidup jujur melalui pembelajaran pendidikan kewarganegaraan di sekolah dasar. Dalam hal ini, pembelajaran pendidikan kewarganegaraan di sekolah dasar penting untuk diselenggarakan karena akan membentuk sikap yang berkarakter bagi peserta didik. Adapun, penelitian ini menggunakan metode kualitatif dengan melakukan studi literatur terhadap pendapat para tokoh dan mengkaji jurnal yang terkait dengan mater. Kesimpulan dari penelitian ini adalah, pendidikan kewarganegaraan di sekolah dasar menjadikan peserta didik menjadi warga negara yang baik karena di dalam muatan materi pembelajaran yang diajarkan terkandung nilai pendidikan karakter salah satunya adalah berperilaku jujur.

Kata Kunci: Pembelajaran PKn di SD, penerapan perilaku jujur, solusi permasalahan kebiasaan menyontek
\end{abstract}

\begin{abstract}
Honest behavior is the key to better education. In this case, education seems to turn a deaf ear to various problems related to honest problems. For that we need a solution to minimize it. A strategic solution to overcome these problems is to carry out civic education learning in elementary schools. The purpose of this research is to apply honest living behavior through civic education learning in elementary schools. In this case, civics education learning in elementary schools is important to be held because it will form a character attitude for students. Meanwhile, this study uses a qualitative method by conducting a literature study on the opinions of the figures and reviewing journals related to the material. The conclusion of this study is that civic education in elementary schools makes students good citizens because the content of the learning materials taught contains the value of character education, one of which is honest behavior.

Keywords: Civics learning in elementary school, application of honest behavior, solution to the problem of cheating habits
\end{abstract}

\section{PENDAHULUAN}

Pendidikan merupakan sebuah upaya menjadikan peserta didik memiliki akhlak yang baik untuk masa depan suatu bangsa. Menurut Yuli Sectio Rini (2013) Pendidikan memiliki peran penting untuk memberdayakan kemampuan dan potensi dalam mengendalikan emosi, meningkatkan kecerdasan, berkarakter sesuai pancasila, dan menjunjung tinggi perilaku sesuai 


\section{AoEJ: Academy of Education Journal \\ Vol. 13 No 1 Tahun 2022}

hak dan kewajiban di masyarakat. Pendidikan tercipta melalui interaksi sadar yang dilakukan segenap elemen pendidikan, misalnya antara guru dan siswa, kurikulum pembelajaran, dan mata pelajaran untuk meunjang pembelajaran siswa. Dengan mempertimbangkan beberapa konsep, Pendidikan dapat diselenggarakan dengan berbagai upaya misalnya dengan pembelajaran pendidikan kewarganegaraan kepada siswa, khususnya pada siswa sekolah dasar.

Mata pelajaran pendidikan kewarganegaraan perlu diajarkan kepada peserta didik berdaya guna meningkatkan penerapan hidup sesuai dengan perilaku yang baik di masyarakat. Menurut Machful Indra Kurniawan (2013) kunci dari penerapan pendidikan yang berkarakter bisa dilihat dari pelaksanaan pendidikan kewarganegaraan di sekolah. Sekolah dasar merupakan fondasi awal sebuah pendidikan, maka dari itu dengan pembelajaran pendidikan kewarganegaraan di sekolah dasar bisa menjadi salah satu strategi untuk menjembatani tujuan pendidikan yang berakhlak mulia sesuai dengan pancasila.

Generasi muda menentukan arah masa depan suatu bangsa. Jika, generasi mudanya tidak menunjukkan sesuatu transisi haluan yang positif. Akan dapat dipastikan arah dari haluan suatu bangsa mengalami kekacauan dalam berbagai aspek. Hal ini sejalan dengan pendapat Awalia Marwah Suhandi dan Dini Anggraeni Dewi (2021) kunci dari pembentukkan suatu bangsa yang baik terletak pada sikap menjunjung tinggi penerapan pancasila oleh generasi mudanya. Pendidikan di Indonesia tidak kekurangan peserta didik yang cerdas, namun pendidikan di Indonesia kekurangan peserta didik yang berperilaku jujur. Hal ini ditunjukkan dengan banyaknya permasalahan terkait perilaku jujur, contohnya adalah kebudayaan menyontek.

Perilaku menyontek merupakan wujud penerapan perilaku tidak jujur di lingkungan sekolah. Dalam hal ini ditemukan berbagai kasus tentang perbuatan yang buruk ini yaitu perilaku menyontek. Tidak berperilaku jujur dengan menyontek ini sudah terjadi sejak lama, sehingga sudah menjadi suatu kebiasaan di lingkungan sekolah. Peserta didik yang menyontek menganggap bahwa jalan satu-satunya menuju nilai yang baik adalah dengan menyontek. Perilaku seperti ini harus dihentikan dan diminimalisir demi kemajuan pendidikan di Indonesia.

Menurut Anugrahening Kushartanti (2009) pendidik harus menanamkan rasa percaya kepada peserta didik dalam pembelajaran. Para guru harus mengubah pemikiran siswa, Karena sejatinya nilai dari kertas ulangan itu tidak akan memengaruhi masa depan, namun akhlak yang sesuai dengan pendidikan karakterlah yang dapat menuntun menuju kesuksesan. 


\section{AoEJ: Academy of Education Journal \\ Vol. 13 No 1 Tahun 2022}

Penerapan perilaku hidup jujur bisa dilakukkan dengan melakukkan pembelajaran pendidikan kewarganegaraan. Dalam pendidikan kewarganegaraan diterapkan pendidikan karakter sebagai wujud implementasi pembelajarannya. Menurut T Heru Nurgiansah (2021) dengan penerapan nilai-nilai yang ada pada pancasila maka akan terciptanya pendidikan yang menjunjung tinggi kejujuran di atas segalanya. Nilai pancasila ada pada muatan PKn di SD, untuk itu harus dimaknai oleh peserta didik sebagai upaya meningkatkan kualitas diri dengan berperilaku jujur dalam kehidupan sehari-hari.

Berdasarkan pemaparan tersebut, pengkaji akan mengkaji secara komperhensif bagaimana pembelajaran pendidikan kewarganegaraan di sekolah dasar dapat mengatasi permasalahan yang sudah mengakar yang melahirkan kebudayaan bahkan kebiasaan di sekolah yaitu tidak berperilaku jujur misalnya menyontek dan berbohong.

\section{METOE PENELITIAN}

Pada metode penelitian setidaknya ditemukan gambaran atau arah penelitian yang akan dikembangkan. Pada penelitian kali ini, digunakan metode penelitian kualitatif. Menurut Conny R Semiawan (2010) mencari definisi secara menyeluruh tentang sesuatu data secara faktual dapat menggunakan penelitian kualitatif. Untuk itu, penelitian kualitatif sudah sangat tepat untuk dijadikan metode dalam penelitan kali ini.

Dalam penelitian kualitatif terdapat berbagai macam teknik untuk memudahkan penelitian, salah satunya adalah studi literature. Menurut Mulyo (2012) peneliti yang menentukakkan apakah kajian ini dapat terselenggara, untuk itu peneliti harus menganalisis beberapa pendapat dan mengambil kesimpulan. Kajian pada penelitian kali ini, membandingkan beberapa pendapat dari sumber-sumber jurnal yang teraktual kemudian dikembangkan, dicatat, dikelola, serta diambil kesimpulannya.

\section{HASIL DAN PEMBAHASAN}

\section{A. Pembelajaran Pendidikan Kewarganegaraan di Sekolah Dasar}

Pembelajaran dapat berlangsung ketika terjadi keharmonisan antara pendidik, peserta didik, dan pengelolaan kelas efektif. Artinya harus mempertimbangkan rasa kemanusiaan di atas segalanya dan memiliki karakter yang kuat untuk hidup yang senantiasa berlaku jujur dalam segala tindakan. Ketika dalam diri seseorang sudah tertanam bagaimana cara 


\section{AoEJ: Academy of Education Journal \\ Vol. 13 No 1 Tahun 2022}

mengimplemetasikan nilai baik dalam diri, maka orang tersebut telah berhasil mencapai tujuan pendidikan yang sesungguhnya. Menurut Tata Herawati Daulae (2014) dalam pembelajaran harus memiliki beberapa komponen yaitu adanya cita-cita yang digapai, yang ingin dicapai, kompetensi materi, tindakan dan strategi, refernsi bacaan, dan bahan penilaian. Pembelajaran pendidikan kewarganegaraan mengandung beberapa esensi mencetak generasi unggul karena mengandung materi pendidikan karakter sesuai dengan sila yang terdapat pada pancasila.

Dalam pendidikan kewarganegaraan terkandung nilai-nilai karakter bangsa yang termuat dalam pendidikan karakter. Menurut Ina Magdalena (2020) wujud dari materi pendidikan kewarganegaraan sebagai berikut:

1. Perilaku Taat

Dalam hal ini wujud yang memuat materi dalam pendidikan kewarganegaraan adalah perilaku taat. Taat dalam hal ini adalah bersikap tunduk dan patuh kepada arahan sang pencipta. Perilaku taat bisa dilakukan dengan cara berdoa ketika hendak memulai pembelajaran.

2. Perilaku Tenggang Rasa

Pada perilaku ini, materi pembelajaran pendidikan kewarganegaraan dapat membuat peserta didik memiliki rasa empati dan saling tolong menolong terhadap satu dengan yang lainnya. Hal ini terwujud ketika peserta didik bisa bekerjasama dalam tugas kelompoknya.

3. Perilaku Cinta Tanah Air

Perilaku ini ditunjukkan pada materi Pendidikan kewarganegaraan yang senantiasa mengandung unsur jiwa patriotisme yang tinggi. Cinta tanah air ini merupakan wujud materi pendidikan kewarganegaraan yang menjadi ciri khas pelajaran ini dipelajari di sekolah dasar.

4. Perilaku Disiplin

Disiplin dalam materi PKn ini adalah bagaimana peserta didik dapat menjalani kehidupannya sesuai dengan aturan yang berlaku dimana peserta didik tinggal. Misalnya ketika guru memberikan aturan tidak boleh telat, maka murid harus menaati peraturan tersebut untuk terciptanya perilaku disiplin. 


\section{AoEJ: Academy of Education Journal \\ Vol. 13 No 1 Tahun 2022}

5. Perilaku Bekerja Sama

Kerja sama dalam hal ini mampu berdiskusi dan mampu menempatkan dirinya sejajar dengan yang lain. Bekerja secara bersama akan mewujudkan pembelajaran yang harmonis dan pekerjaan atau tugas akan cepat terlaksana dengan baik.

6. Perilaku Jujur

Dalam wujud perilaku jujur ini, materi pendidikan kewarganegaraan memuat sebuah konsep yang mudah dipahami oleh peserta didik dan mampu memberikan stimulus untuk senantiasa berperilaku jujur dalam perkataan dan tindakan yang telah dilakukannya. Perilaku jujur merupakan wujud implementasi pembelajaran pendidikan kewarganegaraan yang dapat dilaksanakan dengan baik.

Pendidikan kewarganegaraan di sekolah dasar merupakan suatu upaya menciptakan generasi penerus bangsa yang menjunjung tinggi nilai kejujuran di dalam jiwanya. Menurut Ina Magdalena, Ahmad Syaiful Haq, dan Fadlatul Ramdhan (2020) materi dalam pembelajaran pendidikan kewarganegaraan mengandung konsep mengedepankan perilaku moral yang mampu berfikir dengan logika. Mata pelajaran pendidikan kewarganegaraan terintegrasikan dengan beberapa mata pelajaran lain, sehingga peserta didik dibimbing oleh guru untuk memahami bagaimana cara agar tidak terjadi misskonsepsi pemahaman tentang hidup jujur.

Pendidik harus mampu mengusai metode pembelajaran dalam pendidikan kewarganegaraan. Metode ini dibutuhkan untuk mengubah paradigma lama mengenai mata pelajaran pendidikan kewarganegaraan, menjadi paradigma baru untuk masa depan. Menurut Feri Tirtoni (2016) ciri dari paradigma baru mata pelajaran pendidikan kewarganegaraan adalah (1) membentuk siswa yang dapat mengetahui masalahnya sendiri, (2) melatih siswa menganalisis permasalahnya, (3) membantu siswa menemukan solusi yang tepat bagi suatu permasalahannya.

\section{B. Penerapan Perilaku Jujur Kepada Peserta didik}

Jujur merupakan perilaku yang baik, namun saat ini sulit untuk ditemui dalam dunia pendidikan. semua seakan-akan lupa bahwa esensi pendidikan sesungguhnya adalah bagaimana penerapan pendidikan karakter salah satunya berperilaku jujur dalam kehidupan sehari-hari. Menurut Daviq Chairilsyah (2016) hal yang paling fundamental dalam kehidupan adalah nilai kejujuran. Nilai kejujuran harus diajarkan sedini mungkin. Tanamkan pemikiran bahwa jujur itu 
adalah di atas segalanya. Berikut adalah cara yang dapat dilakukan pendidik untuk menerapkan perilaku jujur kepada peserta didik:

1. Tanamkan Perilaku Jujur secara sederhana

Dalam hal ini pendidik bisa memberi contoh kepada peserta didik mengenai perilaku jujur. Misalnya jujur kepada diri sendiri bahwa sudah melakukkan ibadah tepat waktu, jujur ketika berbicara kepada kedua orang tua, jujur di kalangan masyarakat. Pendidik harus merasakan dan berdialog dengan peserta didik dan tanamkan nilai religius yang kuat kepada peserta didik.

2. Berikan pemahaman bahwa nilai bukan segalanya

Dalam hal ini pendidik bisa memotivasi siswa dengan cara mengatakan bahwa berperilaku jujur itu di atas segalanya. Dalam penerapannya peserta didik tidak akan mendewakan nilai dan mengejar nilai tanpa memerhatikan kejujuran yang ada. penanaman pemahaman ini akan menjadikan peserta didik percaya dan yakin kepada dirinya sendiri.

3. Berikan Pujian

Ketika peserta didik sudah melakukkan sikap hidup jujur dalam kehidupannya, pendidik jangan sampai lupa memberikan sebuah pujian agar peserta didik dapat melakukkan hal baik tersebut secara terus menerus.

Membiasakan hidup jujur di lingkungan sekolah memang sangat sulit, terlebih sistem pendidikan di Indonesia saat ini dirasa hanya memperhatikkan aspek pengetahuan saja tanpa melihat proses perkembangan pembelajaran peserta didik. Usaha berperilaku jujur dapat menciptakan sebuah pemerdekaan belajar yang mengartikan bahwa kejujuran merupakan kunci dari kesuksesan. Menurut Teuku Zulkhairi (2011) Pendidikan di indonesia terlalu berlomba mencapai tujuan berupa nilai, tanpa mempertimbangkan potensi pengelolaan sikap. Perilaku seperti ini harus diminalisir, bahwa sesungguhnya pendidikan itu bukan ajang berpacu dalam nilai semata, namun bagaimana mencetak generasi unggul yang menjunjung tinggi nilai kejujuran.

\section{Permasalahan Perilaku Jujur dalam Pendidikan}

Masalah utama dari perilaku jujur dalam dunia pendidikan adalah kebudayaan menyontek oleh para peserta didik. tidak dapat dipungkiri bahwasannya menyontek pasti pernah dilakukan oleh peserta didik. Menurut Awalia Marwah Suhandi dan Triana Lestari (2021) Perilaku 


\section{AoEJ: Academy of Education Journal \\ Vol. 13 No 1 Tahun 2022}

menyontek adalah sebuah kebiasaan yang muncul secara tidak sengaja, namun diwajarkan terjadi di lingkungan sekolah. Artinya, sebenarnya kebudayaan menyontek ini bisa diatasi, tetapi semua orang memilih diam menanggapi permasalahan ini.

Kegiatan menyontek terjadi disemua tingkatan mulai dari SD sampai kuliah. Jika pada jenjang pendidikan sekolah dasar peserta didik sudah melakukkan kegiatan tersebut, maka peserta didik nantinya akan terus mengulanginya. Dengan demikian, fungsi guru sekolah dasar sangat dibutuhkan. Pendidik di sekolah dasar harus bisa memberikan education kepada peserta didik, bahwa perbuatan ini adalah perbuatan yang tidak mencerminkan akhlak yang baik.

Dari berbagai alasan yang timbul mengenai perilaku menyontek, alasan yang paling banyak dikemukakan adalah takut nilai yang diraih tidak mendapatkan hasil yang maksimal. Menurut Chistine Masada \& Sabrina Dachmiati (2016) menyontek merupakan jalan pintas meraih nilai yang pantas. Maka dari itu diperlukan refleksi menanggapi hal tersebut. Pendidikan seharusnya tidak menekkan peserta didik meraih nilai yang baik, namun diperlukan penilaian

proses dalam sebuah pembelajaran. Pemerintah dan guru harus berkaca dan mengkaji ulang mengapa para peserta didik melakukkan tindakan tersebut, dengan mengkaji hal tersebut dapat ditemukkan sebuah jalan keluar mengenai kebudayaan menyontek tersebut.

Selain karena takut nilai tidak maksimal, faktor yang mengakibatkan peserta didik menyontek adalah perilaku yang malas dalam belajar. Peran guru yang harus dilakukkan dalam hal ini adalah memberikan motivasi dan menyiapkan strategi apa yang tepat untuk mengatasi hal tersebut. Cari tahu keinginan apa yang diinginkan oleh siswa agar terciptanya iklim belajar yang menyenangkan dengan mengedepankan nilai kejujuran.

Selain peran guru yang harus ditingkatkan dalam kebiasaan menyontek ini, peran peserta didik juga dibutuhkan. Setelah guru membimbing dan mengajarkan berbagai pemahaman tentang perilaku hidup jujur dengan mengikuti pembelajaran pendidikan kewarganegaraan, selanjutnya peserta didik harus benar-benar menerapkan perilaku itu di dalam dirinya. Peserta didik harus sadar mengenai pentingnya berperilaku jujur di sekolah, rumah, dan masyarakat.

\section{Solusi Mengatasi Permasalahan Tidak Berperilaku Jujur}

Seperti pemaparan pada point-point sebelumnya, dikatakan bahwa perilaku jujur sudah mengakar dan sulit sekali dihilangkan dari jati diri peserta didik sekarang. Terlebih dimasa pandemi potensi peserta didik melakukkan tindakan kecurangan itu sangat besar sekali. Untuk 


\section{AoEJ: Academy of Education Journal \\ Vol. 13 No 1 Tahun 2022}

itu diperlukan sebuah upaya pemberantasan hal tersebut. Cara yang paling efektif adalah melalui pembelajaran yang dilakukan.

Pengajaran ini, merupakan hal dasar yang wajib diberikan kepada siswa. Muatan pembelajaran dasar termuat berbagai macam konsep, proses, dan kegiatan untuk mencapai tujuan pendidikan sesungguhnya. Pendidikan karakter adalah salah satu wujud nyata adanya mata pelajaran PKn di SD. Dengan mempelajari hal tersebut, maka dapat mengatasi permasalahan yang ada pada dunia pendidikan. Adapun manfaat pengajaran PKn:

1. Menjadikkan siswa sebagai masyarakat baik

Tujuan utama pembelajaran merupakan menciptakan siswa yang memiliki berkarakter.

Peserta didik harus senantiasa berkontribusi untuk kemajuan bangsanya. Dalam pembelajaran ini, siswa diperkenalkan bagaimana dapat bertoleransi dan tenggang rasa kepada orang lain serta berkontribusi secara aktif untuk kemajuan bangsanya.

2. Memunculkan kesadaran akan pentingnya hak dan kewajiban warga negara

Pembelajaran telah dilakukan diberbagai tingkatan kelas, misalnya menghormati hak orang lain, mendapatkan haknya, serta harus menjalankan kewajiban sebagai warga negara, baik di rumah, sekolah, maupun di masyarakat. Hal ini menunjukkan bahwa peserta didik diharapkan setelah mempelajari PKn di sekolah dasar dapat menjalankan hak dan kewajiban secara benar.

3. Membentuk jiwa nasionalisme dan patriotisme yang tinggi

Manfaat pendidikan kewarganegaraan diajarkan sedini mungkin adalah untuk menumbuhkan rasa jiwa nasionalisme kebangsaan. Dalam hakikatnya, nasionalisme merupakan wujud dari penerapan pembelajaran PKn yang dilakukkan dengan efektif. Pembelajaran PKn dengan mengenal lambang pancasila dan menyanyikan lagu nasional bisa dilakukkan guru untuk memupuk jiwa nasionalisme di sekolah dasar kelas awal.

4. Menerapkan perilaku hidup jujur

Manfaat yang paling terasa dari implementasi pembelajaran pendidikan kewarganegaraan di sekolah dasar adalah peserta didik mengaplikasikan hidup jujur dimanapun dan kapanpun. Pendidikan karakter yang di dalamnya terdiri dari nilai kejujuran dapat mengendalikan peserta didik untuk termotivasi untuk melakukkan tindakan perilaku hidup jujur tersebut. 


\section{AoEJ: Academy of Education Journal \\ Vol. 13 No 1 Tahun 2022}

Menurut Sukadi (2013) perlu dikembangkan nilai relugius taat kepada tuhan agar mampu mengendalikan dirinya agar terhindar dari perilaku buruk. Dalam pendidikan kewarganegaraan nilai spiritual merupakan materi pemahaman yang menjadi cita-cita pendidikan nasional.

\section{SIMPULAN}

Terkait pemaparan pembahasan di atas, kesimpulan dari pemaparan tersebut adalah bahwa pengajaran ini adalah salah satu solusi yang strategis untuk menerapkan perilaku hidup jujur dilingkungan rumah, sekolah, dan masyarakat. dengan memerhatikan beberapa konsep materi yang dikaji dalam pembelajaran pendidikan kewarganegaraan, guru dan peserta didik dapat menerapkan perilaku hidup jujur yang berkeadilan di lingkungan sosialnya. Pembelajaran pendidikan kewarganegaraan menyediakan keleluasaan menyampaikan pemikirannya untuk senantiasa berguna dan bermanfaat bagi orang banyak. Menanamkan sifat jujur pada peserta didik, dapat mengurangi perilaku kurang baik ketika dewasa kelak. Jujur pada diri sendirilah yang menjadikan kunci bagi kesuksesan kehidupan, setelah mampu jujur kepada diri sendiri, peserta didik dapat mengimpementasikan pikirannya untuk melakukan sikap jujur karena sejatinya jujur itu sebuah perbuatan yang indah.

\section{SARAN}

Saran bagi pemerintah adalah penerapan dan pengembangan kurikulum harus sangat memerhatikan situasi dan kondisi yang ada pada dunia pendidikan, pemerintah harus menciptakan sebuah regulasi tentang penerapan penerapan perilaku hidup jujur di lingkungan masyarakat khususnya di lingkungan sekolah. saran bagi Pendidik dalam hal ini harus terus memberikan pemahaman untuk siswa agar senantiasa berperilaku hidup jujur dan jangan jadikan nilai menjadi tolak ukur kecerdasan peserta didik. saram bagi peserta didik adalah dalam jiwa peserta didik harus ditanamkan pemikiran bahwa jujur harus di atas segalanya.

\section{DAFTAR PUSTAKA}

Budiutomo, T. (2013). PENDIDIKAN KEWARGANEGARAAN DALAM MEMBENTUK KARAKTER BANGSA. Academy of Education Journal, 4(1). https://doi.org/10.47200/aoej.v4i1.94 
Chairilsyah, D. (2016). Metode dan Teknik Mengajarkan Kejujuran Pada Anak Sejak Usia Dini. Jurnal Educhild. Vol 05, 8-14

Daulae, T.H. (2014). Menciptakan Pembelajaran yang Efektif. Jurnal Forum Pedagogik, Vol $06,131-150$

Haris, L. (2017). IMPLEMENTASI PEMBELAJARAN PENDIDIKAN KEWARGANEGARAAN DALAM PEMBENTUKAN PERILAKU SISWA BERWARGA NEGARA YANG BAIK DI SD JUARA KELURAHAN BACIRO KECAMATAN GONDOKUSUMAN KOTA YOGYAKARTA TAHUN PELAJARAN 2016. Academy of Education Journal, 8(2), 226-269. https://doi.org/10.47200/aoej.v8i2.372

Kurniawan, M.I. (2013). Integrasi Pendidikan Karakter Ke Dalam Pembekajaran Kewarganegaraan di Sekolah Dasar. Jurnal Pemikiran dan Pengembangan SD. Vol 01, $37-45$

Kushartanti, A. (2009). Perilaku Menyontek Ditinjau Dari Kepercayaan Diri. Jurnal Indigenus. Vol 11, 38-46

Kusumawati, I. (2012). PEMBENTUKAN KARAKTER SISWA MELALUI PENDIDIKAN KEPRAMUKAAN. Academy of Education Journal, 3(1). https://doi.org/10.47200/aoej.v3i1.85

Kusumawati, I., \& Kriswanto, Y. (2013). PENDIDIKAN KARAKTER DI SEKOLAH DASAR NEGERI BRENGOSAN 1 KECAMATAN NGAGLIK KABUPATEN SLEMAN. Academy of Education Journal, 4(1). https://doi.org/10.47200/aoej.v4i1.93

Magdalena, I. et al., (2020). Pembelajaran Pendidikan Kewarganegaraan di Sekolah Dasar Negeri Bojong 3 Pinang. Jurnal Bintang : Pendidikan dan Sains. Vol 02, 418-430

Masada, C. \& Dachmiati, S. (2016). Faktor Pemengaruh Perilaku Siswa dan Mahasiswa Menyontek. Jurnal Sosio E-Kons. Vol 08, 227-233

Mulyo. (2012). Model Pembelajaran Inovatif. Yogyakarta: Gava media

Nurgiansah, T. H. (2021). Pendidikan Pancasila Sebagai Upaya Membentuk Karakter Jujur. Jurnal Pendidikan Kewarganegaraan Undiksha. Vol 09, 33-41

Paiman, P., \& Temu, T. (2013). TANGGUNG JAWAB DAN KINERJA PESERTA DIDIK DALAM MENGERJAKAN PEKERJAAN RUMAH MATA PELAJARAN PENDIDIKAN KEWARGANEGARAAN DI SD MUHAMMADIYAHWIROBRAJAN II YOGYAKARTA. Academy of Education Journal, 4(1). https://doi.org/10.47200/aoej.v4i1.95

Rini, Y.L. (2013). Pendidikan : Hakekat, Tujuan, dan Proses. Jurnal Pendidikan dan Seni Universitas Negeri Jogyakarta. 1-13

Semiawan, C.R. (2010). Metode Penelitian Kualitatif. Jakarta: Grasindo

Suhandi, A.M. \& Dewi, D.A. (2021). Implementasi Nilai Pancasila Terhadap Esensi Nilai Humanisme dalam Kehidupan Bermasyarakat di Kalangan Generasi Muda. JepJurnal. Vol 03, 37-43 


\section{AoEJ: Academy of Education Journal \\ Vol. 13 No 1 Tahun 2022}

Suhandi, A.M. \& Lestari, T. (2021). Pengaruh Kebudayaan Menyontek Terhadap Perkembangan Kemandirian Anak: Upaya Pemberantasan Kebiasaan Menyontek di Lingkungan Sekolah. Jurnal AoEJ. Vol 12, 285-293

Sukadi. (2013). Belajar dan Pembelajaran PKn SD sebagai Yadnya Dalam Rangka Perwujudan Dharma Agama dan Dharma Negara Berbasis Konstruktivisme.Jurnal Cakrawala Pendidikan. Vol 02, 196-206

Tirtoni, F. (2016). Pembelajaran PKn di Sekolah Dasar: Inovasi Melalui Strategi Habituasi dan Program Kegiatan Sekolah Berkarakter. Yogyakarta: CV Buku Baik Yogyakarta

Wati, R. (2016). STUDI PERBEDAAN ANTARA PRESTASI BELAJAR MANDIRI DENGAN BELAJAR PENDAMPINGAN MATA PELAJARAN PENDIDIKAN KEWARGANEGARAAN PADA SISWA TUNA WICARA SMALB. Academy of Education Journal, 7(2), 123-134. https://doi.org/10.47200/aoej.v7i2.407

Zulkhairi, T. (2011). Membumikan Karakter Jujur Dalam Pendidikan di Aceh. Jurnal Ilmiah Islam Futura. Vol 11, 105-115 